\title{
Educação Física na educação (inclusiva?) de jovens e adultos: um retrato da produção científica na área
}

\section{RESUMO}

A Educação de Jovens e Adultos (EJA) é uma modalidade de ensino não-regular para indivíduos que tiveram acesso tardio à escola. Este estudo objetivou investigar a produção científica da área da Educação Física (EF) para analisar os debates sobre inclusão escolar e EJA. Para tal, houve uma revisão sistemática no portal CAPES, utilizando-se as palavras-chave: EJA, EF, inclusão, escola, currículo e "formação de professores" e suas combinações. Foram encontrados sete artigos para a discussão desta pesquisa e classificados em três categorias. $\mathrm{Na}$ análise de conteúdo, emergiram aspectos discutidos nas produções e tornou-se possível traçar pontos comuns relativos nas pesquisas. A inclusão escolar, de maneira geral, vem sendo discutida à medida que a literatura apresenta a ocorrência de situações excludentes e a necessidade de se estudar medidas para minimizá-las, criando oportunidades de participação efetiva por todos e todas nas aulas de EF para esta modalidade de ensino.

PALAVRAS-CHAVE:Educação física; Educação de jovens e adultos; Inclusão; Produção científica

\begin{tabular}{|c|}
\hline $\begin{array}{r}\text { Débora Le } \\
\text { Mestre em Educ } \\
\text { Universidade Federal do Rio } \\
\text { scola de Educação Física e Despo } \\
\text { Jar } \\
\text { deboralpeluso } \\
\text { @ https://orcid.org/0000-0003 }\end{array}$ \\
\hline $\begin{array}{r}\text { Ana Lidia Felippe } \\
\text { Doutora er } \\
\text { Universidade Federal do Rio } \\
\text { iscola de Educação Física e Despo } \\
\text { alfelippe } \\
\text { (1) https://orcid.org/0000-000 }\end{array}$ \\
\hline $\begin{array}{r}\text { Michele Pereira de Souza } \\
\text { Doutora er } \\
\text { Universidade Federal do Rio } \\
\text { scola de Educação Física e Despo } \\
\text { Jar } \\
\text { michelepsf22 } \\
\text { https://orcid.org/0000-0003 }\end{array}$ \\
\hline $\begin{array}{r}\text { Marcelo Leonel Peluso } \\
\text { Graduando em Psicologia } \\
\text { Universidadedo Estado do Rio de Janeiro, } \\
\text { Instituto de Psicologia, Rio de Janeiro, Brasil } \\
\text { marceloleonelpeluso@gmail.com } \\
\text { @ https://orcid.org/0000-0002-3669-3561 }\end{array}$ \\
\hline
\end{tabular}




\title{
Physical Education in the (inclusive?) adult and youth education: a portrait of the scientific production in the field
}

\begin{abstract}
Adult and youth education (AYE) is a non-regular education modality to individuals that had a later access to schooling. This study aimed at investigating the scientific production in the Physical Education (PE) field in order to analyze debates on school inclusion and AYE. Thereby, a systematic review at the CAPES portal was performed, employing the keywords: AYE, PE, inclusion, school, curriculum and "teachers' formation" and its combinations. To this research discussion, seven articles were found and classified in three categories. At the content analysis, aspects discussed in these productions were highlighted and it was possible to draw common points related to the researches. The school inclusion, generally, has been discussed as the literature shows the occurrence of excluding situations and the need to study measures to minimize them, creating opportunities of an effective participation by all students in the FE classes for this education modality.
\end{abstract}

KEYWORDS: Physical education; Adult and youth education; Inclusion; Scientific production

\section{Educación Física en la educación (¿inclusiva?) de jóvenes y adultos: un retrato de la producción científica en el área}

\section{RESUMEN}

Educación de Jóvenes y Adultos (EJA) es una modalidad de educación no-regular para individuos que tuvieron acceso tardío a la escuela. Este estudio tuvo como objetivo investigar la producción científica en el área de Educación Física (EF), con el fin de analizarlos debates sobre la inclusión escolar y EJA. Para ello, se realizó una revisión sistemática en el portal CAPES, utilizando las palabras clave: EJA, EF, inclusión, escuela, currículum y "capacitación docente" y sus combinaciones. Se encontraron siete artículos para la discusión de esta investigación y fueron clasificados entre categorías. En el análisis de contenido, se destacaron los aspectos discutidos en estas producciones y fue posible establecer puntos comunes relacionados con la investigación. La inclusión escolar, en general, ha sido discutida mientras la literatura muestra la ocurrencia de situaciones de exclusión y la necesidad de estudiar medidas para minimizarlas, creando oportunidades para la participación efectiva de todos y todas en las clases de EF para esta modalidad de educación.

PALABRAS-CLAVE: Educación física; Educación de jóvenes y adultos; Inclusión; Producción científica 


\section{INTRODUÇÃO}

A Educação de Jovens e Adultos (EJA) é uma modalidade da educação básica destinada àqueles que não tiveram a oportunidade de acessar ou continuar os estudos nas etapas dos ensinos fundamental e médio na idade apropriada. Constituída como instrumento para a aprendizagem e educação ao longo da vida, a EJA promove articulação com a educação profissional, além de proporcionar a construção de conhecimentos de maneira diferenciada para o público a que se propõe. De acordo com o Parecer da Câmara de Educação Básica do Conselho Nacional de Educação (CNE / CEB 11/2000, p. 05), que trata das Diretrizes Curriculares Nacionais para a Educação de Jovens e Adultos, “[...] a EJA é uma categoria organizacional constante da estrutura da Educação Nacional com finalidades e funções específicas”. Esta afirmação determina uma especificidade para a EJA, o que marca um modo diferenciado de ação.

O Parecer propõe um importante processo de reorganização curricular para as turmas da EJA, cuja definição ficou sob a responsabilidade de cada Secretaria de Educação das instâncias Estadual e Municipal. Outro ponto relevante deste documento diz respeito à apresentação das três funções desta modalidade de ensino: reparadora, equalizadora e qualificadora. A primeira diz respeito à exclusão histórica daqueles jovens e adultos; a segunda é relativa à ampliação da EJA para a diversidade social brasileira, através da possibilidade do retorno educacional desses sujeitos e, a terceira demarca o sentido permanente da educação.

A Lei 9.394/96 (BRASIL,1996) estabelece as Diretrizes e Bases da Educação Nacional e dedica a Seção V do Capítulo II para a EJA: “Os sistemas de ensino manterão cursos e exames supletivos, que compreenderão a base nacional comum do currículo, habilitando ao prosseguimento de estudos em caráter regular" (Art. 38). Ora, se as disciplinas que compõem o currículo das turmas da EJA estão de acordo com a base curricular das turmas do ensino regular, a Educação Física, assim como, a Matemática, a História, a Geografia, o Português, dentre outras, também deve ser oferecida para os Jovens e Adultos, nos Ensinos Fundamental e Médio.

Sobre o Ensino Médio, cabe ressaltar que a Base Nacional Comum Curricular (BRASIL, 2018), documento que define aprendizagens necessárias para o desenvolvimento de estudantes na Educação Básica do país, foi atualizada e homologada pelo Ministério da Educação (MEC) em 2017, porém não considerou a diversidade presente nas turmas da EJA, não apresentando nenhum capítulo ou seção específica para esta ou qualquer outra modalidade de ensino diferente da regular.

Rodrigues e Alves Junior (2016) apontam que os/as estudantes que formam este cenário escolar pertencem a diferenciadas esferas da sociedade e possuem características e necessidades específicas. Na EJA, a presença da diversidade é marcada pela idade, gênero, ritmo variado de 
aprendizagem, ocupações diárias, sexualidade, dentre outros atributos. Razão pela qual, a escola deve oferecer um ensino de qualidade atento às peculiaridades apresentadas pelos sujeitos dos processos de ensino e aprendizagem.

Nas aulas de Educação Física, — e pelas características próprias da disciplina — algumas diferenças ficam evidenciadas, como por exemplo, a maior frequência de aulas práticas, onde o corpo é exposto e o movimento é estudado, analisado e vivenciado. Desse modo, uma das funções da Educação Física escolar é apresentar a importância do corpo em movimento. De que maneira, a escola se prepara para reconhecer as diferenças concernentes aos/às estudantes da EJA? Qual é o papel do/a professor/a de Educação Física nesse contexto? Quais são as possibilidades de intervenção por parte do/a professor/a para a educação justa e igualitária em direitos? Como proporcionar a oportunidade de participação de todos e de todas nas aulas de Educação Física na EJA?

Fonseca (2014, p. 55), ancorada em Sawaia (2014), Booth e Ainscow (2011), Santos, Fonseca e Melo (2009), apresenta a inclusão em educação como um “[...] mote dialético, processual e dinâmico [...]", que atenta para as singularidades e necessidades de cada um e busca, constantemente, alternativas para a participação efetiva de todas as pessoas. Esta concepção de inclusão surge como uma forma de olhar, entender, acolher e educar toda a comunidade escolar, uma vez que, as culturas, as políticas e as práticas inclusivas coexistem em ações coletivas que vão além de enfrentar situações excludentes de toda ordem. A perspectiva inclusiva envolve a desconstrução de estereótipos, a ressignificação de conceitos, a percepção da diversidade, o exercício da empatia e o respeito às diferenças.

Ainda que tenhamos avançado no campo teórico em relação a uma perspectiva ampla de inclusão que não se volta somente a uma parte da população - mas que reconhece o direito de todas as pessoas em suas diferenças — atualmente temos presenciado evidentes retrocessos no campo político nesse sentido. Para citar dois exemplos mais recentes e emblemáticos, tivemos a extinção da SECADI (Secretaria de Educação Continuada, Alfabetização, Diversidade e Inclusão) e a reformulação da Política Nacional de Educação Especial na perspectiva da Educação Inclusiva PNEEPEI (BRASIL, 2008).

A SECADI, criada em 2004 e extinta em janeiro de 2019 (BRASIL, 2019), era uma secretaria com importante articulação no que tange à inclusão, visto que propunha e desenvolvia programas e projetos para a alfabetização, educação de jovens e adultos, educação do campo, educação escolar indígena, educação em áreas remanescentes de quilombos, educação em direitos humanos, educação ambiental e educação especial na perspectiva inclusiva (BRASIL, 2012). Portanto, com a extinção da SECADI, tais ações foram dissolvidas em outros espaços com menos 
prestígio, implicando em retrocessos no campo dos direitos sociais e educacionais, conquistados após muita mobilização e luta dos movimentos sociais envolvidos em assegurar o direito à educação com qualidade e equidade.

A PNEEPEI (BRASIL, 2008), que propunha a educação especial perpassando transversalmente por todos os níveis, etapas e modalidades de ensino, foi reformulada e transformada em Política Nacional de Educação Especial (BRASIL, 2020) - evidenciando esfacelamento de todos os esforços empreendidos no país ao longo dos últimos anos para que a segregação escolar não perdurasse. Esta reformulada política não faz sequer menção à EJA, enquanto a PNEEPEI se preocupava em apontar que "[...] na modalidade de educação de jovens e adultos e educação profissional, as ações da educação especial possibilitam a ampliação de oportunidades de escolarização, formação para ingresso no mundo do trabalho e efetiva participação social” (BRASIL, 2008, p.12, grifo nosso).

Tendo em vista que o público da EJA é diverso e que esta modalidade de ensino, segundo Oliveira (2016), é um direito social e uma responsabilidade pública, supõe-se que a inclusão permeia este universo. Contudo, ao refletir sobre a educação inclusiva, a Educação Física e a EJA, surgem alguns questionamentos: É inclusivo todo trabalho desenvolvido nas aulas de Educação Física na EJA? De que forma os/as docentes de Educação Física têm se preparado para atuar de maneira inclusiva na escola? Quais discussões a área, enquanto campo científico, tem priorizado acerca dessa temática?

De acordo com Lüdorf (2017), analisar as produções científicas é um dos caminhos para compreender o desenvolvimento de uma área de conhecimento, pois observar os tipos de pesquisa recorrentes, levantar os temas problematizados, identificar as metodologias utilizadas e averiguar, até mesmo, a forma através da qual estes produtos são publicados, significa conhecer o que vem sendo priorizado na academia e através desse panorama torna-se possível identificar o estreitamento ou afastamento da ciência com a prática.

As produções acadêmicas são veiculadas de formas variadas na comunidade e estão presentes em trabalhos oriundos de grupos de pesquisa, monografias, dissertações, teses, etc - que, por sua vez, são apresentadas em eventos científicos, transformadas em livros e/ou publicadas em revistas, em forma de artigos. Considera-se, assim, que os artigos científicos são um produto de grande legitimidade acadêmica, principalmente, em relação ao procedimento rigoroso e detalhista de submissão em periódicos.

O objetivo deste trabalho é investigar as produções científicas da área, privilegia-se aqui as produções em formato de artigo, a fim de analisar se a inclusão vem sendo debatida nas pesquisas em Educação Física na EJA, e, de que maneira isso ocorre. A relevância desta revisão justifica-se 
na pertinência e atualidade do tema, no sentido de identificar possíveis lacunas ou potências nesse campo da EJA em específico.

Na presente pesquisa, foram analisados os conteúdos de artigos sobre a Educação Física e a EJA, visando compreender se a inclusão vem ganhando espaço nas discussões de cunho acadêmico. Adiante, será apresentado um panorama geral da produção científica analisada, ressaltando os assuntos abordados nas pesquisas; seus autores, datas e revistas de publicação; objetivos, metodologias e resultados. Por fim, será realizada a discussão dos elementos que se destacam (ou que estão silenciados) sobre o objeto deste estudo.

\section{PROCEDIMENTOS METODOLÓGICOS}

A presente investigação, de abordagem qualitativa, caracteriza-se como exploratória e descritiva, recorrendo à técnica da análise documental, a qual se baseia na coleta de materiais que ainda não receberam tratamento analítico (GIL, 2010). Para este fim, as seguintes etapas foram seguidas: reunir os documentos (no caso, os artigos), descrever seus conteúdos e efetuar uma primeira ordenação das informações.

Para mapear os artigos, foi selecionado o Portal de Periódicos da CAPES que abarca diferentes bases de dados nas quais diversos periódicos relativos à Educação, Educação Física e afins são indexados. $\mathrm{O}$ filtro da língua portuguesa foi utilizado visto que o objeto do presente trabalho é regional e detém caráter sociocultural - intenciona acompanhar o fenômeno no Brasil. Algumas palavras-chave e seus respectivos sinônimos foram selecionados em conformidade com os Descritores em Ciências da Saúde (DeCS), outras, porém, foram inclusas, pois, compõem as discussões nos campos da Educação Física Escolar - mesmo que não tenham sido cadastradas como um descritor.

Uma revisão sistemática foi realizada utilizando-se as seguintes palavras-chave: <educação física $>$; <EJA>; <inclusão>; <escola>; <currículo>; <formação de professores $>$. Diversas combinações foram feitas com o objetivo de captar maior quantidade de artigos em alinhados com a finalidade deste trabalho. Os termos "currículo" e "formação de professores" foram utilizados por se correlacionarem com o assunto. A varredura foi realizada entre os meses de outubro a novembro de 2018 e foram selecionados os artigos publicados nos últimos cinco anos — é característica desta pesquisa avaliar o que tem sido produzido atualmente.

Os textos encontrados foram sistematizados em planilhas do Microsoft Excel contendo título, autoria, periódico, ano de publicação, tema, objetivo, metodologia, principais resultados, 
resumo e palavras-chave - tornando possível, assim, realizar um mapeamento abrangente da produção acadêmica e identificar se a inclusão, de alguma maneira, foi retratada.

O tratamento dos dados foi realizado nos termos da Análise de Conteúdo Temático, que de acordo com Turato (2003, p. 442), "procura nas expressões verbais ou textuais os temas gerais recorrentes que fazem a sua aparição no interior de vários conteúdos [...]”. Neste processo, evidenciaram-se as problemáticas apresentadas nas pesquisas analisadas, sendo posteriormente categorizadas a fim de melhor elucidar a natureza dos enfoques temáticos dos artigos, que serão apresentados a seguir:

\section{ANÁLISE E DISCUSSÃO}

\section{Panorama geral da produção científica pesquisada}

O número de artigos encontrados ao final da busca no Portal de Periódico da CAPES foi 257 e a distribuição de resultados por combinação de palavras-chave está apresentada na tabela 1:

Tabela 1 - Número de artigos encontrados por combinação de palavras-chave

\begin{tabular}{|c|l|c|}
\hline & \multicolumn{1}{|c|}{ Combinação de palavras-chave } & Número de artigos \\
\hline 1 & "Educação Física"; EJA & 15 \\
\hline 2 & EJA; inclusão & 78 \\
\hline 3 & "Educação Física"; EJA; escola & 13 \\
\hline 4 & "Educação Física"; EJA; currículo & 09 \\
\hline 5 & "Educação Física"; inclusão; currículo & 74 \\
\hline 6 & "Educação Física"; EJA; "formação de professores” & 07 \\
\hline 7 & "Educação Física"; inclusão; "formação de professores" & 41 \\
\hline 8 & "Educação Física"; EJA; inclusão; escola & 08 \\
\hline 9 & "Educação Física"; EJA; inclusão; currículo & 07 \\
\hline 10 & "Educação Física"; EJA; inclusão; formação de professores” & 05 \\
\hline & & $\mathbf{2 5 7}$ \\
\hline
\end{tabular}

Fonte: dados compilados pelos autores

Cabe ressaltar que o número apresentado é resultado das diversas combinações realizadas, e, portanto, não expressa quantitativamente a publicação acadêmica centrada nesses tópicos, uma vez que, determinados artigos se encontram repetidos devido à superposição de palavras-chave. 
Adicionando a repetição ao critério de exclusão, foram observados os títulos, resumos e palavras-chave de cada trabalho, identificando e excluindo aqueles que não se referiam ao tema-alvo desta pesquisa. Na fase de pré-análise, como esperado, pesquisas relacionadas à EJA, à inclusão, à Educação Física surgiram, porém, de forma isolada, e, por esta razão, não foram consideradas na análise.

Ainda durante esta etapa, foram detectadas tanto pesquisas que retratavam a inclusão na EJA, quanto aquelas que focavam na diversidade de estudantes desta modalidade — eram, no entanto, produções de outras áreas disciplinares como a Matemática, a Física e o Inglês. É interessante constatar que a inclusão na EJA vem sendo alvo de questionamentos também em outras áreas, por mais que em algumas pesquisas haja a limitação do conceito de educação inclusiva, assim como também é perceptível na Educação Física.

Consoante à finalidade da presente investigação e objetivando compreender se a inclusão permeava, em algum momento, o desenvolvimento das produções — todos os artigos que tratavam a Educação Física e a EJA foram selecionados. O material documentado foi representado por sete produções científicas perfiladas de acordo com a natureza do estudo. O quadro abaixo apresenta os artigos analisados:

Quadro 1 - Dados de identificação dos artigos analisados:

\begin{tabular}{|c|c|c|c|c|c|}
\hline & Título & Autoria & Ano & Revista & Objetivo do artigo \\
\hline 1 & $\begin{array}{l}\text { Juvenilização da } \\
\text { EJA: repercussões } \\
\text { na Educação Física }\end{array}$ & $\begin{array}{l}\text { Franchi; } \\
\text { Günther }\end{array}$ & 2018 & Motrivivência & $\begin{array}{l}\text { Problematizar o aumento do } \\
\text { público adolescente na } \\
\text { Educação de Jovens e Adultos } \\
\text { (EJA), relacionando esse fato a } \\
\text { aspectos legais e } \\
\text { sociopedagógicos. }\end{array}$ \\
\hline 2 & $\begin{array}{l}\text { Efeito das aulas de } \\
\text { Ginástica Escolar } \\
\text { nos níveis de } \\
\text { Atividade Física: } \\
\text { Jump na Educação } \\
\text { de Jovens e Adultos } \\
\text { (EJA) }\end{array}$ & Lemes et al & 2017 & $\begin{array}{l}\text { Revista } \\
\text { Brasileira de } \\
\text { Prescrição e } \\
\text { Fisiologia do } \\
\text { Exercício }\end{array}$ & $\begin{array}{l}\text { Verificar o efeito de aulas de } \\
\text { ginástica escolar em mini } \\
\text { trampolim nos níveis de } \\
\text { atividade física de escolares da } \\
\text { EJA. }\end{array}$ \\
\hline 3 & $\begin{array}{l}\text { O PROEJA na } \\
\text { Educação do } \\
\text { Campo: uma análise } \\
\text { curricular da } \\
\text { disciplina de } \\
\text { Educação Física }\end{array}$ & Adona & 2017 & $\begin{array}{l}\text { Revista } \\
\text { Labor }\end{array}$ & $\begin{array}{l}\text { Conceituar as bases que } \\
\text { fundamentam o currículo da } \\
\text { educação física escolar na } \\
\text { perspectiva da educação do } \\
\text { campo e dos alunos do } \\
\text { PROEJA; compreender de que } \\
\text { maneira a disciplina de } \\
\text { educação física pode se tornar } \\
\text { significativa para o aluno do } \\
\text { PROEJA dentro da realidade }\end{array}$ \\
\hline
\end{tabular}




\begin{tabular}{|c|c|c|c|c|c|}
\hline & & & & & $\begin{array}{l}\text { do campo; e relatar sobre a } \\
\text { aplicabilidade da inclusão da } \\
\text { disciplina de educação física no } \\
\text { currículo do PROEJA da } \\
\text { referida instituição. }\end{array}$ \\
\hline 4 & $\begin{array}{l}\text { Perfil de qualidade } \\
\text { de vida e atividade } \\
\text { física habitual de } \\
\text { adultos participantes } \\
\text { das aulas de } \\
\text { Educação Física da } \\
\text { Educação de Jovens } \\
\text { e Adultos (EJA) }\end{array}$ & $\begin{array}{l}\text { Rodrigues; } \\
\text { Alves Jr }\end{array}$ & 2016 & $\begin{array}{l}\text { Revista } \\
\text { Brasileira de } \\
\text { Prescrição e } \\
\text { Fisiologia do } \\
\text { Exercício }\end{array}$ & $\begin{array}{c}\text { Descrever o perfil de qualidade } \\
\text { de vida e de atividade física } \\
\text { habitual de adultos } \\
\text { participantes das aulas de } \\
\text { Educação Física da Educação } \\
\text { de jovens e Adultos, a partir da } \\
\text { aplicação dos questionários } \\
\text { SF-36 e Baecke modificado, } \\
\text { respectivamente. } \\
\end{array}$ \\
\hline 5 & \begin{tabular}{|c|} 
Relações entre a \\
Educação Física \\
Escolar e Educação \\
de Jovens e Adultos \\
no interior do \\
Colégio Brasileiro \\
de Ciências do \\
Esporte (CBCE): \\
sujeitos, \\
concepções, \\
impasses e \\
perspectivas \\
\end{tabular} & Oliveira & 2016 & $\begin{array}{c}\text { Revista } \\
\text { Pedagógica }\end{array}$ & $\begin{array}{c}\text { Analisar as relações entre a } \\
\text { Educação Física Escolar e a } \\
\text { Educação de Jovens e Adultos } \\
\text { presentes nas produções } \\
\text { acadêmicas do CBCE, entidade } \\
\text { científica que congrega } \\
\text { pesquisas em Educação Física } \\
\text { no Brasil desde } 1978 .\end{array}$ \\
\hline 6 & $\begin{array}{c}\text { "Pensei que tava na } \\
\text { aula de Ciências" ou } \\
\text { os significados da } \\
\text { Educação Física na } \\
\text { Educação de Jovens } \\
\text { e Adultos } \\
\end{array}$ & $\begin{array}{l}\text { Reis; } \\
\text { Molina } \\
\text { Neto }\end{array}$ & 2014 & $\begin{array}{c}\text { Pensar a } \\
\text { Prática }\end{array}$ & $\begin{array}{l}\text { Compreender os sentidos que } \\
\text { os estudantes trabalhadores da } \\
\text { Educação de Jovens e Adultos } \\
\text { (EJA) atribuem à Educação } \\
\text { Física escolar. }\end{array}$ \\
\hline 7 & $\begin{array}{l}\text { A cultura escolar da } \\
\text { Educação Física no } \\
\text { EJA: o paradoxo } \\
\text { entre a ruptura com } \\
\text { a noção de atividade } \\
\text { e a falta da prática } \\
\text { corporal }\end{array}$ & $\begin{array}{l}\text { Pich; } \\
\text { Fontoura }\end{array}$ & 2013 & $\begin{array}{l}\text { EducaciónFisi } \\
\text { ca yCiencia }\end{array}$ & $\begin{array}{l}\text { Investigar a relação de uma } \\
\text { professora de Educação Física } \\
\text { com o universo do trabalho } \\
\text { docente em uma escola pública } \\
\text { da cidade de Curitiba - PR, na } \\
\text { qual os autores encontraram } \\
\text { um aspecto peculiar da prática } \\
\text { pedagógica da EF. }\end{array}$ \\
\hline
\end{tabular}

Fonte: dados compilados pelos autores

Diante do quadro acima, é possível analisar a base onde os trabalhos foram construídos. Os títulos dos sete estudos fazem menção à Educação Física e os autores de todos os trabalhos possuem formação na área. Embora cada estudo apresente um enfoque sobre a EJA, todos a priorizam como objeto de pesquisa. 
No que tange à divulgação, observou-se que há uma variedade nos periódicos em que os artigos foram publicados. Algumas reservam maior espaço para pesquisas de caráter pedagógico e sociocultural (Motrivivência, Pensar a Prática, Revista Labor e Revista Pedagógica) e outras abarcam maior quantidade de pesquisas da subárea biodinâmica, em interfaces com a saúde e atividade física.

De uma maneira geral, a quantidade de artigos que atendem aos critérios estabelecidos por esta investigação é pequena e uma hipótese que justificasse essa ocorrência foi elaborada durante a percepção de determinadas características dos estudos — quanto a sua epistemologia e a publicação dessas sete produções.

De acordo com a classificação proposta em Manoel e Carvalho (2011), o perfil dos trabalhos traçados como alvo de busca nesta investigação se enquadra, a princípio, como pedagógico e/ou sociocultural, por tratar temas na perspectiva da sociologia e da filosofia e investigar questões relativas ao desenvolvimento curricular, aos métodos de ensino, além de envolver aspectos metodológicos, sociais, políticos e filosóficos da educação.

Peluso (2016) observa que o espaço para o desenvolvimento e para a divulgação de pesquisas desta linha é escasso, principalmente quando comparado às condições oferecidas para as produções da linha biodinâmica - constatação que pode justificar o resultado da varredura realizada nesta ocasião.

A maior parte dos artigos selecionados converge com as vertentes pedagógica e sociocultural por possuírem as características apontadas anteriormente. Ademais, os procedimentos metodológicos adotados são coerentes com pesquisas de cunho qualitativo: observação participante, estudo de caso, entrevistas semiestruturadas, dentre outras (LÜDORF, 2017).

Dois dos sete artigos buscados nesta revisão sistemática possuem relação com a subárea biodinâmica da Educação Física. Foram identificadas influências das Ciências Naturais e da Saúde, a utilização de métodos quantitativos, a realização de tratamento estatístico de dados e a publicação em periódicos da área de Fisiologia do Exercício. No entanto, uma vez que possuem como objeto de pesquisa a EJA, foram incluídos na análise.

\section{Sobre especificamente a produção científica analisada}

As categorias de análise, - revelando os enfoques temáticos dos artigos — as relações das problemáticas levantadas com a Educação Física enquanto campo científico e as ligações ou ausência delas com a inclusão em educação encontram-se apresentadas a seguir: 


\section{1) Análise das categorias temáticas dos artigos}

Ao observar os temas sobre os quais as investigações se debruçam, foi possível estabelecer três categorias temáticas: Aulas de Educação Física na EJA, Estudantes da EJA e Produção de conhecimento em Educação Física na EJA, conforme gráfico a seguir.

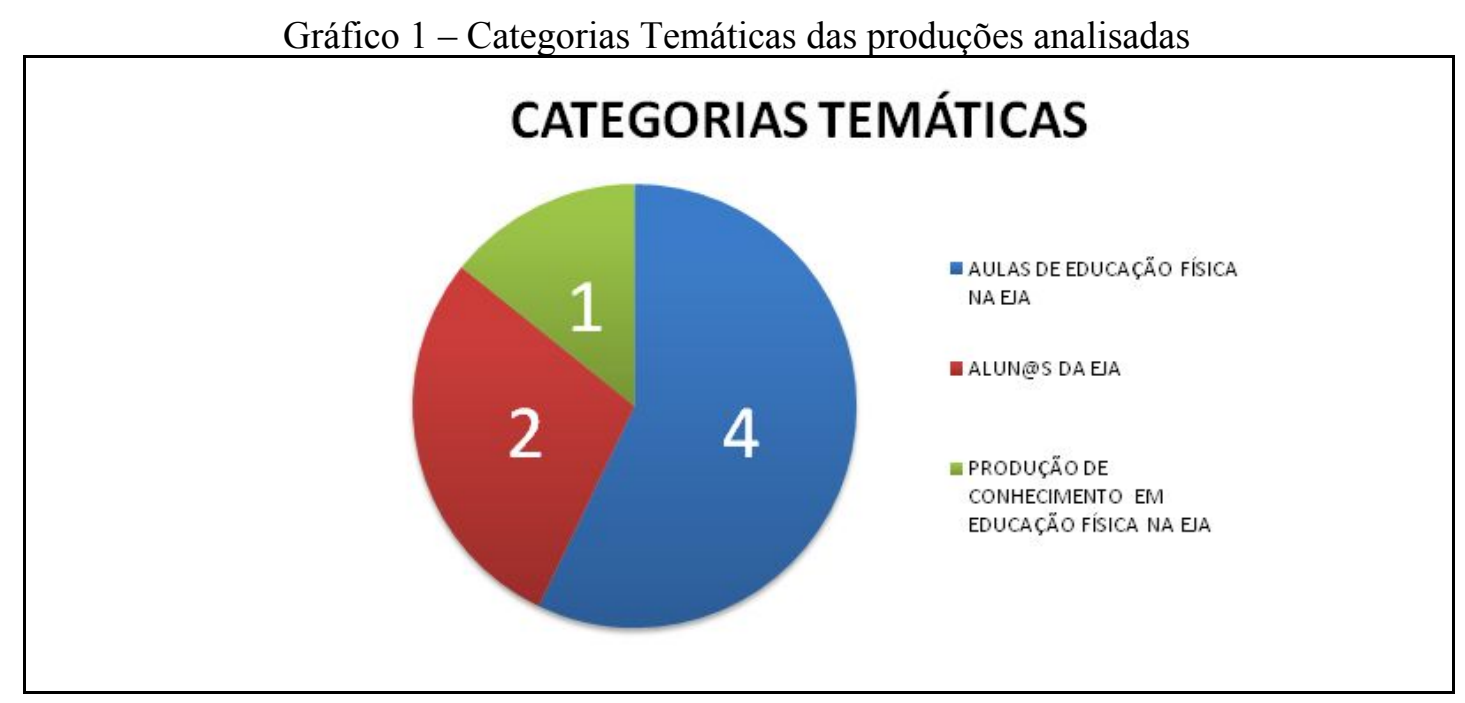

Fonte: dados compilados pelos autores

A categoria Aulas de Educação Física na EJA conta com quatro estudos, sendo dessa forma, a predominante. São eles "Efeito das aulas de Ginástica Escolar nos níveis de Atividade Física: “Jump na Educação de Jovens e Adultos (EJA)”, “O PROEJA na Educação do Campo: uma análise curricular da disciplina de Educação Física", "Pensei que tava na aula de Ciências" ou os significados da Educação Física na Educação de Jovens e Adultos" e "A cultura escolar da Educação Física no EJA: o paradoxo entre a ruptura com a noção de atividade e a falta da prática corporal".

Os autores dos trabalhos referendados se reportam aos conteúdos das aulas de Educação Física de forma mais precisa, analisam o currículo da disciplina e/ou realizam pesquisas sobre a aplicação de alguma prática durante a aula. Peluso e Lüdorf (2013) realizaram uma pesquisa, de aspecto regional, sobre a formação do professor de Educação Física e identificaram que são poucos os espaços de discussão sobre a EJA. O resultado apresentado pelas autoras indicou que os professores atuantes em turmas da EJA não refletiram esta realidade em sua formação e precisaram recorrer a cursos de formação continuada e a pesquisas para que pudessem planejar suas aulas. Este argumento parece revelar um dos motivos para a existência de pesquisas sobre as aulas de Educação Física na EJA, fatia da Educação Física Escolar ainda pouco estudada (RODRIGUES; ALVES JUNIOR, 2016). 
A Educação Física Escolar busca a sua legitimidade enquanto disciplina escolar desde que foi incluída obrigatoriamente na Educação Básica. $\mathrm{Na}$ década de 1970, houve grande questionamento sobre a relevância (porque ensinar), a finalidade (para quê ensinar), os métodos (como ensinar) e os conteúdos (o que ensinar) da Educação Física na escola. Nesta época, surgiram abordagens teórico-metodológicas que apresentavam diferentes concepções de Educação Física Escolar (DARIDO, 2003).

Ainda não há uma sistematização dos conteúdos desta disciplina nos diferentes segmentos de ensino (apesar de existirem documentos oficiais que apresentam sugestões e/ou orientações a respeito), tendo em vista que os conteúdos são elencados pelo professor de acordo com a concepção na qual este profissional se apoia. Dessa maneira, justifica-se o grande número de pesquisas que possuem as aulas de Educação Física Escolar como alvo.

Os trabalhos intitulados "Juvenilização da EJA: repercussões na Educação Física" e "Perfil de qualidade de vida e atividade física habitual de adultos participantes das aulas de Educação Física da Educação de Jovens e Adultos (EJA)" compõem a categoria Estudantes da EJA, visto que são dedicados a esta parcela da comunidade escolar. Um trata o fenômeno da grande entrada de jovens nas turmas e o outro realiza uma coleta de dados com sujeitos escolhidos perante a diversidade da população que frequenta as aulas da EJA.

O Documento Nacional Preparatório à VI Conferência Internacional de Educação de Adultos, elaborado pelo Ministério da Educação, posiciona-se em relação à multiplicidade de fatores específicos da EJA. Acerca do conjunto amplo e heterogêneo de jovens e adultos que compõem o corpo discente desta modalidade, a comissão organizadora pontua algumas das diferenças que podem estar presentes na EJA:

[...] mulheres, homens, crianças, adolescentes, jovens, adultos, idosos, pessoas com necessidades especiais, indígenas, afrodescendentes, descendentes de portugueses e de outros europeus, asiáticos, de latino-americanos, entre outros. A diversidade que constitui a sociedade brasileira abrange jeitos de ser, viver, pensar e agir que se enfrentam (BRASIL, 2009, p.28).

Diante do exposto, não restam dúvidas de que os sujeitos contemplados pela EJA pertencem a diferentes contextos socioculturais e ambientais, o que aumenta: 1. a riqueza da convivência humana; 2. a responsabilidade em oferecer possibilidades de inserção e permanência na escola por parte de diferentes estudantes, que cresce proporcionalmente à medida que estes vivenciam situações excludentes. e 3. o aumento gradativo de estudos sobre este público.

Por fim, a categoria Produção de Conhecimento em Educação Física na EJA representada pelo artigo "Relações entre a Educação Física Escolar e Educação de Jovens e Adultos no interior 
do Colégio Brasileiro de Ciências do Esporte (CBCE): sujeitos, concepções, impasses e perspectivas" demonstra que a Educação Física enquanto campo científico tem destinado interesse nos últimos anos, mesmo que timidamente, às questões que a EJA apresenta.

$\mathrm{O}$ artigo analisou 21 trabalhos sobre a Educação Física e a EJA apresentados em congressos científicos, de 2007 a 2015. Esse dado vai ao encontro do que Reis e Molina Neto (2014, p. 637) apresentam: "A EJA, ao longo do tempo, tem sido objeto de diversos estudos no sentido de compreender as razões de sua existência como modalidade educacional”. Entretanto, a quantidade total de trabalhos oriundos do grupo temático Educação Física Escolar neste período foi 806, o que traduz o estágio inicial das pesquisas em Educação Física sobre a EJA.

De acordo com Lüdorf (2002), ocorreu na década de 1990 uma mudança no universo da pesquisa em Educação Física. As abordagens qualitativas passaram a ser incorporadas gradativamente, de maneira significativa, embora houvesse preponderância em relação àquelas de cunho quantitativo. Ao que tudo indica, o número de pesquisas calcadas nas Ciências Humanas e Sociais, como é o caso do estudo representado por esta categoria, aumentou exponencialmente.

Ainda segundo Lüdorf (2017, p. 27), “a área avança continuamente na produção de conhecimento científico e as temáticas a serem exploradas ampliaram-se sobremaneira, inclusive com a incorporação de estudos sobre questões ligadas à saúde, gênero, corpo, cultura, dentre outras, pouco contempladas anteriormente". O fenômeno apresentado pela autora explica as novas pesquisas, sobre as produções científicas a fim de compreender o processo de seu desenvolvimento na academia, assim como é a intenção deste trabalho e do artigo pertencente à categoria analisada.

\section{2) Educação Física na Educação (Inclusiva?) de Jovens e Adultos}

$\mathrm{Na}$ tabela 1, nota-se um número considerável de produções quando mencionado o termo "inclusão". Percebe-se a recorrência da caracterização de pessoas com deficiência como público-alvo de discussões sobre inclusão em educação. Para Mantoan (2015), a educação inclusiva visa desconstruir a ideia de integração das pessoas com deficiência, onde os sujeitos adaptam--se às condições existentes. Pelo contrário, a inclusão propõe mudanças nas instituições e práticas sociais, no acolhimento de todas e todos, respeitando as diferenças. A educação inclusiva contribui (ou tem o intuito de contribuir) para uma maior igualdade de oportunidades a todos os membros da sociedade, sem necessariamente referir-se somente às pessoas com deficiência (LAGO; SANTOS, 2011).

Faz-se necessário ratificar que a educação na perspectiva inclusiva não se limita somente aos que apresentam dificuldades escolares, mas considera o direito de participação a todas as pessoas. 
Muito embora se pese historicamente esta associação estrita às pessoas com deficiência, o termo não resume um único grupo de pessoas. Booth e Ainscow (2011) enfatizam que a inclusão envolve e beneficia professores, estudantes, pessoal administrativo, na intenção de obter sucesso no processo educativo.

$\mathrm{Na}$ Educação Física, segundo Fonseca e Ramos (2017), é importante compreender o princípio da inclusão como o acesso irrestrito de estudantes com necessidades educacionais diversas às aulas desta disciplina, levando em consideração suas singularidades. A Inclusão em Educação detém uma visão mais ampla, na proposta de identificar e resolver dificuldades emergentes do contexto escolar. Práticas inclusivas envolvem processos de aumento da participação dos/as estudantes e redução das exclusões.

Nesse sentido, é possível afirmar que a inclusão, enquanto combate às situações excludentes, permeia o desenvolvimento dos seis artigos estudados. Apenas um trabalho não apresenta nenhuma preocupação com a temática. Neste, existe o levantamento de um desconforto por parte dos autores sobre a assiduidade dos/as estudantes: “[...] na EJA há elevada flutuação na presença dos alunos durante as aulas, devido a não obrigatoriedade de comparecimento nas práticas de Educação Física para alguns desses sujeitos.” (LEMES et al., 2017, p. 866). Todavia, o estudo não reflete sobre nenhuma possibilidade de mudança desse quadro através de práticas inclusivas.

Ao contrário, a evasão, as diferentes faixas etárias dos estudantes e as situações de vulnerabilidade social são apresentadas como barreiras constantes (incômodas) no dia a dia docente. Os autores supervalorizam o aumento do nível de atividade física dos/as estudantes demonstrado como resultado de sua intervenção e questionam sobre a intensidade e a prática de atividade física não serem recorrentes nas aulas de Educação Física. Há de se refletir que a carência do olhar inclusivo, bem como a rasa consolidação dos meios de acessibilidade para aprendizagem, pode favorecer a evasão.

Quanto ao público da EJA, os autores, fundamentados no enfoque biologicista, citam as características dos sujeitos: idade, sexo, medidas antropométricas (estatura e massa corporal), dentre outras. Na conclusão, os pesquisadores sugerem que os professores planejem as aulas de Educação Física Escolar com embasamento na teoria do treinamento físico, considerando intensidade, progressão e continuidade como aspectos relevantes ao cronograma de ensino da disciplina, afirmando ser possível - mesmo sob as condições adversas encontradas na EJA (que não são apresentadas no artigo). Não cabe atribuir valores nesta ocasião, julgando como certas ou erradas as intenções das pesquisas e sim analisá-las de acordo com o propósito deste trabalho. Diante do exposto, fica estabelecido o rompimento da posição apresentada pelo Art. com a concepção de educação inclusiva que está sendo defendida neste trabalho. 
Em contrapartida, os seis outros artigos discutem a inclusão de alguma maneira. Alguns aspectos comuns foram pontuados nestes trabalhos. Todos os estudos revelaram inquietação com a evasão nas aulas de Educação Física e a maioria deles elencou como hipóteses para a explicação desse fenômeno: 1. a falta de interesse por parte dos/as estudantes, 2. a ausência de significado da disciplina de Educação Física por parte do corpo discente, 3. a redução da sua importância destinada a um momento de descontração, esvaziada de conhecimento conceitual, por parte de estudantes, professores e direção e 4. a flexibilidade na presença da aula como garantida, em lei, por parte das pessoas que: tenham filho, idade acima de 30 anos, sejam militares ou apresentem "necessidades especiais" (ADONA, 2017). Cabe ressaltar que tal trecho de lei pressupõe um padrão que exclui justamente a diversidade de histórias de vida dos/as estudantes que frequentam a escola.

$\mathrm{Na}$ tentativa de superar esse quadro, apresentou-se como discurso comum que as aulas de Educação Física deveriam ser desenvolvidas a partir das representações, das ideias e dos interesses dos/as estudantes - como parte de seus universos - para alavancar sua participação. De frente com a diversidade percebida na EJA, é um desafio para o/a professor/a e para todo o corpo pedagógico construir um planejamento adequado às especificidades desse público, que anteriormente era, em sua maioria, composto por adultos, mas que vem contando cada vez mais com maior quantidade de jovens (FRANCHI, GÜNTHER, 2018; RODRIGUES, ALVES JUNIOR, 2016). Entendemos que esse cenário representa uma heterogeneidade rica e com grande potencial de interações dialógicas inclusivas, segundo Candau (2020), baseada em Emilia Ferreiro, considerando as diferenças como vantagem pedagógica.

Para contribuir com a gestão e a organização escolar nesta perspectiva inclusiva, ou seja, para que sejam concedidas oportunidades de participação efetiva de todos e todas nas aulas e na escola, algumas etapas de preparação são apontadas pelos estudos como de fundamental importância durante esse processo: a apreciação da literatura científica, PCNs, diretrizes curriculares, juntamente com a pesquisa e prática pedagógica diária dos professores, a formação inicial e continuada destes profissionais e o estabelecimento de uma relação bem próxima com os/as estudantes (PICH; FONTOURA, 2013).

Alguns aspectos associados à aula de Educação Física que cada artigo vivencia são compartilhados: aulas teóricas com a explanação de diversos conteúdos como a preparação do corpo para o trabalho, a promoção da saúde (REIS; MOLINA NETO, 2014), a utilização de material didático em forma de textos sobre a História da Educação Física, Yoga, Respiração, Dança, Dança Afro, Esportes, Jogos Cooperativos, Diversidade, Orientação sexual, Vigorexia, Lazer, Alongamento, Obesidade (PICH; FONTOURA, 2013) e a aplicação de oficinas de ginástica, dança e slackline (OLIVEIRA, 2016). 
Contudo, de acordo com Franchi e Günther (2018), a inclusão social e a diversidade devem ser princípios norteadores do processo de planejamento da educação física na EJA, tendo em vista a centralidade na formação humana em detrimento de uma formaçãotécnico-instrumental voltada apenas à preparação para o mercado de trabalho. Mais do que a consolidação da presença da disciplina nesta modalidade de ensino, trata-se de fazê-la através de perspectivas críticas que representem uma formação conectada às necessidades e às especificidades da EJA.

Como defende Adona (2017, p.18), “atualmente, almeja-se que as aulas de Educação Física possam oportunizar o aluno a vivenciar a diversidade das práticas corporais por meio de conhecimentos que enfatizam a cultura corporal de movimento, considerando a evolução individual de cada educando." Nesta perspectiva, a atribuição do status de mera atividade e não de uma área de conhecimento escolar (OLIVEIRA, 2016) tende a ser superada, demonstrando na prática o potencial inclusivo da Educação Física na escola.

\section{CONSIDERAÇÕES FINAIS}

Partindo do pressuposto que não são somente as concepções que definem a Educação de Jovens e Adultos na vertente da escolarização e sim, especialmente, a práxis, objetivou-se, neste trabalho, observar se a inclusão em educação é contemplada nas discussões sobre a Educação Física na EJA, uma vez que, enquanto direito, esta modalidade de ensino não se realiza de modo inclusivo quando restrita ao simples acesso.

A diversidade característica do público da EJA requer valores fundamentais, que orientem a prática dos professores nessa modalidade, assim como o respeito às diferenças como parte do processo de humanização. Pensar em inclusão e diferenças é desenvolver relações mútuas que aproximam a escola e as comunidades do entorno, agindo com foco na colaboração em combate às situações excludentes.

Ao analisar as produções científicas destinadas ao estudo da Educação Física na EJA, foi possível identificar um número reduzido em relação às temáticas, quando interligadas. No tocante aos direitos elementares dos sujeitos que estão inseridos nessa realidade, notou-se tanto no desenvolvimento de pesquisas quanto na existência de políticas públicas, um afastamento, o que reafirma o processo de exclusão e de barreiras, no que tange à participação e à aprendizagem.

Nos artigos referentes às aulas de Educação Física, observou-se que os autores trouxeram para discussão elementos, sobre os quais se fizeram emergir, no tocante ao aspecto do planejamento, a necessidade de considerar a educação inclusiva. Ressalta-se que esse aspecto 
didático é de profunda relevância, não só em relação às especificidades do público da EJA, mas também no que diz respeito à diversidade de sujeitos que convivem no lócus da escola.

Conclui-se, diante do objetivo traçado para este artigo, que a inclusão de modo geral vem sendo contemplada quando se discute academicamente a Educação Física na EJA, mesmo que ainda algumas distorções quanto à concepção de educação inclusiva se façam presentes. Destaca-se a importância da prática dos professores e a contribuição das políticas públicas para a crescente demanda de estudos nessa modalidade da Educação Básica. Reconhece-se a urgência em estudos nesta área, principalmente com o aumento da migração de jovens para a EJA, fenômeno que tende a aumentar a recorrência de situações excludentes, reforçando, dessa forma, a necessidade de se estudar medidas para combatê-las, no sentido de criar oportunidades de participação efetiva para todos e todas nas aulas de Educação Física para esta modalidade de ensino.

\section{REFERÊNCIAS}

ADONA, Sâmmya Faria. O Proeja na educação do campo: uma análise curricular da disciplina da Educação Física. Revista Labor, Fortaleza/CE, v. 01, n. 17, p. 13-26, 2017.

BOOTH, Tony; AINSCOW, Mel. Index Para a Inclusão. Desenvolvendo a aprendizagem e a participação na escola. Produzido pelo LaPEADE, 2011.

BRASIL. Decreto No 10.502, de 30 de setembro de 2020. Diário Oficial da União. Edição: 189, Seção: 1, Página: 6. Brasília, DF, set. 2020. Disponível em:

https://www.in.gov.br/en/web/dou/-/decreto-n-10.502-de-30-de-setembro-de-2020-28052994. Acesso em: 1 out. 2020

BRASIL.Decreto Nº 9.465, de 2 de janeiro de 2019. Diário Oficial da União. Edição: 1-B, Seção: 1 Extra, Página: 6, Brasília, DF, 2019. Disponível em:

https://www.in.gov.br/materia/-/asset_publisher/Kujrw0TZC2Mb/content/id/57633286 . Acesso em 1 out. 2020

BRASIL. Ministério da Educação. Base Nacional Comum Curricular. 2018. Disponível em: http://basenacionalcomum.mec.gov.br. Acesso em: 02 out 2018.

BRASIL.Decreto No 7.690, de 2 de março de 2012. Presidência da República, Casa Civil, Brasília, DF, 2012. Disponível em: http://www.planalto.gov.br/ccivil 03/_Ato2011-2014/2012/Decreto/D7690.htm. Acesso em 1 out. 2020

BRASIL. Ministério da Educação. Secretaria de Educação Continuada, Alfabetização e Diversidade. Documento Nacional Preparatório à VI Conferência Internacional de Educação de Adultos (VI CONFINTEA) / Ministério da Educação (MEC). - Brasília: MEC; Goiânia: FUNAPE/UFG, 2009.

BRASIL. Ministério da Educação. SECADI. Política Nacional de Educação Especial na Perspectiva da Educação Inclusiva. Brasília, DF, jan. 2008. Disponível $\mathrm{em}:$ http://portal.mec.gov.br/index.php?option=com docman\&view=download\&alias=16690-politica-nacion al-de-educacao-especial-na-perspectiva-da-educacao-inclusiva-05122014\&Itemid=30192 . Acesso em: 1 out. 2020 
BRASIL. Ministério da Educação. LDB: Lei de Diretrizes e Bases da Educação Nacional: lei no 9.394, de 20 de dezembro de 1996, que estabelece as diretrizes e bases da educação nacional. Brasília: Câmara dos Deputados, Edições Câmara, 1996.

CANDAU, Vera Maria. Didática, Interculturalidade e Formação de professores: desafios atuais. Revista Cocar. Edição Especial N.8. Jan./Abr./ 2020 p. 28-44.

DARIDO, Suraya. Educação Física na Escola: Questões e Reflexões. Rio de Janeiro: Editora Guanabara, 2003.

FRANCHI, Silvester; GÜNTHER, Maria Cecília Camargo. Juvenilização da EJA: repercussões na Educação Física. Motrivivência, Florianópolis/SC, v. 30, n. 53., p. 209-225, maio/2018.

FONSECA, Michele Pereira de Souza da. Formação de professores de Educação Física e seus desdobramentos na perspectiva dos processos de inclusão/exclusão: reflexões sobre Brasil e Portugal. Tese (Doutorado em Educação) - Faculdade de Educação, Universidade Federal do Rio de Janeiro, Rio de Janeiro, 2014.

FONSECA, Michele Pereira de Souza da; RAMOS, Maitê. Inclusão em movimento: discutindo a diversidade nas aulas de educação física escolar. In: PONTES JUNIOR, José Airton de Freitas (Org.). Conhecimentos do professor de educação física escolar [livro eletrônico]. Fortaleza, CE: EdUECE, 2017, p 184-208.

GIL, Antonio Carlos. Métodos e técnicas de pesquisa social. 6. ed. São Paulo: Atlas, 2010.

LAGO, Mara; SANTOS, Mônica Pereira dos. Inclusão em Educação: Desafios da Formação Docente. In: Anais do III Seminário de Educação Brasileira. Plano Nacional de Educação: Questões Desafiadoras e Embates Emblemáticos. Campinas: CEDES, p. 944-958, 2011.

LÜDORF, Silvia Maria Agatti. Metodologia da Pesquisa: do projeto ao trabalho de conclusão de curso. Curitiba: Appris, 2017.

LÜDORF, Silvia Maria Agatti. Panorama da pesquisa em Educação Física da década de 90: análise dos resumos de dissertações e teses. Revista da Educação Física/UEM, Maringá, v. 13, n. 2, p. 19-25, 2002.

MANOEL, Edison de Jesus; CARVALHO, Yara Maria de. Pós-Graduação na educação física brasileira: a atração (fatal) para a biodinâmica. Educação e Pesquisa, São Paulo, v. 37, n. 2, p. 389-406, mai./ago., 2011.

MANTOAN, Maria Teresa Eglér.Inclusão escolar. O que é? Por quê? Como fazer? 1. ed. São Paulo: Summus, 2015.

MINISTÉRIO DA EDUCAÇÃO. Conselho Nacional de Educação. Parecer CNE/CEB 11/2000. Brasília: Câmara de Educação Básica, 2000.

OLIVEIRA, Cláudio Márcio. Relações entre a educação física escolar e a educação de jovens e adultos no interior do colégio brasileiro de ciências do esporte (cbce): sujeitos, concepções, impasses e perspectivas. Revista Pedagógica, Chapecó, v. 18, n. 39, p. 151-173, set./dez. 2016.

PELUSO, Débora Leonel. A pesquisa sociocultural e pedagógica nos programas de Pós-Graduação Stricto Sensu em Educação Física no Rio de Janeiro. Dissertação (Mestrado em Educação Física) - Escola de Educação Física e Desportos, Universidade Federal do Rio de Janeiro, Rio de Janeiro, 2016.

PELUSO, Débora Leonel; LÜDORF, Silvia Maria Agatti. Educação Física na EJA: refletindo sobre a formação do professor. In: IX SIMPOED - Simpósio de formação e profissão docente. Caderno de Programação e Resumos, Ouro Preto, p. 39-251, 2013. 
PICH, Santiago; FONTOURA, Mariana Purcote. A cultura escolar: da educação física no EJA: o paradoxo entre a ruptura com a noção de atividade e a falta da prática corporal. Educación Física y Ciencia, v. 15, n. $1,2013$.

REIS, José Antônio Padilha dos; MOLINA NETO, Vicente. "Pensei que tava na aula de ciências" ou os significados da Educação Física na Educação de Jovens e Adultos. Pensar a Prática, Goiânia, v. 17, n. 3, p. 636-650, jul./set., 2014.

RODRIGUES, Gabriel Dias; ALVES JUNIOR, Edmundo de Drummond. Perfil de qualidade de vida e atividade física habitual de adultos participantes das aulas de Educação Física da Educação de Jovens e Adultos (EJA). Revista Brasileira de Prescrição e Fisiologia do Exercício, São Paulo, v. 10, n. 62, p.734-740, nov./dez., 2016.

SANTOS, Mônica Pereira dos; FONSECA, Michele Pereira de Souza da; MELO, Sandra. Inclusão em Educação: diferentes interfaces. Curitiba, CRV, 2009.

SAWAIA, Bader. (Org.). As artimanhas da Exclusão - análise psicossocial e ética da desigualdade social. Petrópolis: Vozes, 2014.

TURATO, Egberto Ribeiro. Tratado da metodologia da pesquisa clínico-qualitativa: construção teórico-epistemológica, discussão comparada e aplicação nas áreas da saúde e humanas. 2. ed. Petrópolis: Vozes, 2003.

\section{NOTAS DE AUTOR}

AGRADECIMENTOS - Não se aplica.

CONTRIBUIÇÃO DE AUTORIA - Não se aplica.

FINANCIAMENTO - Não se aplica.

CONSENTIMENTO DE USO DE IMAGEM - Não se aplica.

APROVAÇÃO DE COMITÊ DE ÉTICA EM PESQUISA - Não se aplica.

CONFLITO DE INTERESSES - Não há conflitos de interesses.

\section{LICENÇA DE USO}

Os autores cedem à Motrivivência - ISSN 2175-8042 os direitos exclusivos de primeira publicação, com o trabalho simultaneamente licenciado sob a Licença Creative Commons Attribution Non-Comercial ShareAlike (CC BY-NC SA) 4.0 International. Esta licença permite que terceiros remixem, adaptem e criem a partir do trabalho publicado, desde que para fins não comerciais, atribuindo o devido crédito de autoria e publicação inicial neste periódico desde que adotem a mesma licença, compartilhar igual. Os autores têm autorização para assumir contratos adicionais separadamente, para distribuição não exclusiva da versão do trabalho publicada neste periódico (ex.: publicar em repositório institucional, em site pessoal, publicar uma tradução, ou como capítulo de livro), com reconhecimento de autoria e publicação inicial neste periódico, desde que para fins não comerciais e compartilhar com a mesma licença.

\section{PUBLISHER}


Universidade Federal de Santa Catarina. Programa de Pós-Graduação em Educação Física. LaboMídia - Laboratório e Observatório da Mídia Esportiva. Publicado no Portal de Periódicos UFSC. As ideias expressadas neste artigo são de responsabilidade de seus autores, não representando, necessariamente, a opinião dos editores ou da universidade.

\section{EDITORES}

Mauricio Roberto da Silva, Giovani De Lorenzi Pires, Rogério Santos Pereira.

\section{EDITORA DE SEÇÃO}

Bianca Natália Poffo

\section{REVISÃO DO MANUSCRITO E METADADOS}

João Caetano Prates Rocha; Keli Barreto Santos.

\section{HISTÓRICO}

Recebido em: 14 de agosto de 2020.

Aprovado em: 01 de dezembro de 2020. 